\title{
IMPLEMENTASI VIRTUAL BUSINESS CARD BERBASIS ANDROID MENGGUNAKAN AUGMENTED REALITY
}

\author{
Bambang Satrio*1, Agus Suryanto $^{2}$, Anggraini Mulwinda ${ }^{3}$, Khoirudin Fathoni ${ }^{4}$ \\ 1,2,3,4 Teknik Elektro, Universitas Negeri Semarang \\ Email: ${ }^{1}$ bambang.satrio04@gmail.com, ${ }^{2}$ agusku2@mail.unnes.ac.id, ${ }^{3}$ anggrainimulwinda@mail.unnes.ac.id, \\ ${ }^{4}$ khoirudinfathoni@mail.unnes.ac.id \\ *Penulis Korespondensi
}

(Naskah masuk: 08 November 2019, diterima untuk diterbitkan: 19 Juli 2021)

\begin{abstract}
Abstrak
Kartu bisnis masih sering digunakan pada saat ini, namun ada beberapa fungsi yang masih dapat dioptimalkan untuk menutupi kekurangan pada kartu bisnis agar tidak tertinggal dan tergantikan. Kartu bisnis memiliki keterbatasan dalam menampilkan informasi dan tidak interaktif, sehingga kurang menarik untuk digunakan. Teknologi Augmented Reality (AR) dapat membuat kartu bisnis konvensional menjadi kartu bisnis digital (Virtual Business Card). Virtual Business Card dapat menampilkan banyak informasi yang sebelumnya tidak dapat ditampilkan pada kartu bisnis konvensional, dan lebih interaktif dalam menampilkan informasi sehingga dapat menarik minat pengguna. Metode pengembangan yang digunakan dalam pembuatan aplikasi Virtual Business Card adalah Agile Development jenis Extreme Programming. Langkah-langkah penelitian ini adalah Planning, Design, Coding, dan Testing. Pada pengujian aplikasi ini, dilakukan dengan pengujian alpha berupa functional testing (uji black box) dan pengujian beta berupa usability testing (uji ahli media dan uji pengguna aplikasi). Penelitian ini menghasilkan aplikasi Virtual Business Card yang berisi data informasi digital yang dapat digunakan untuk keperluan pribadi. Dari hasil pengujian yang dilakukan, aplikasi dapat dikategorikan "Sangat Baik" sehingga aplikasi dapat dinyatakan layak untuk digunakan sebagai informasi digital pribadi. Berikut ini hasil dari masingmasing pengujian. Hasil pengujian alpha berupa functional testing, yaitu uji black box mendapatkan persentase $100 \%$. Hasil pengujian beta berupa usability testing, yaitu uji ahli media mendapatkan persentase $89,88 \%$ dan uji pengguna mendapatkan persentase $84 \%$.
\end{abstract}

Kata kunci: Kartu Bisnis, Virtual Business Card, Augmented Reality, Marker, Platform Android, Agile Development.

\section{IMPLEMENTATION OF VIRTUAL BUSINESS CARD BASED ON ANDROID USING AUGMENTED REALITY}

\begin{abstract}
Business cards are still often used today, but some functions can still be optimized to cover the shortcomings of business cards, so they are not left behind and replaced. Business cards have limitations in displaying information and are not interactive, making them less attractive to use. Augmented Reality (AR) technology can make conventional business cards into digital business cards (Virtual Business Cards). Virtual Business Cards can display much information that previously could not be displayed on conventional business cards and is more interactive in displaying information so that it can attract the user's interest. The development method used in making Virtual Business Card applications is the Extreme Programming type of Agile Development. The steps of this research are Planning, Design, Coding, and Testing. In testing this application, alpha testing is done in the form of functional testing (black box test) and beta testing in the form of usability testing (media expert test and application user test). This research resulted in a Virtual Business Card application that contains digital information data that can be used for personal use. From the results of tests conducted, the application can be categorized as "Very Good" so that the application can be declared eligible for use as personal digital information. The following are the results of each test. Alpha test results in the form of functional testing, namely, the black box test get a percentage of $100 \%$. The results of beta testing are in the form of usability testing, i.e., media expert tests get a percentage of $89.88 \%$, and user tests get a percentage of $84 \%$
\end{abstract}

Keywords: Business Cards, Virtual Business Cards, Augmented Reality, Marker, Android Platform, Agile Development. 


\section{PENDAHULUAN}

Kartu nama (Name Card) merupakan sebuah kartu kecil yang berisi data diri dan berguna sebagai media penyampaian informasi dalam sebuah perkenalan formal. Salah satu fungsi dari sebuah kartu nama adalah untuk menyampaikan informasi tentang perorangan atau sebuah perusahaan, oleh karena itu salah satu kegunaan kartu nama digunakan sebagai sebuah kartu bisnis (Business Card). Kartu bisnis memberikan kesempatan seseorang untuk dapat lebih membuka diri karena pada kartu bisnis terdapat informasi berisi nama perusahaan, logo, alamat, nomor telepon, nomor fax., situs website dan email (Syukri and Setiawan, 2017, p.26)

Kartu bisnis masih sangat sering digunakan seperti pada perjalanan bisnis ataupun sebuah pertemuan, namun ada beberapa kekurangan yang akan membuat kartu bisnis terasa tertinggal dan akhirnya akan tergantikan. Kartu bisnis memiliki keterbatasan untuk menampilkan informasi dan tidak banyak perbedaan yang terdapat pada satu kartu bisnis dengan kartu bisnis lainnya, sehingga terkesan monoton dan tidak menarik. Pada perkembangan teknologi seperti saat ini harusnya kartu bisnis bukanlah hanya sebuah potongan kertas persegi yang berisi beberapa informasi saja, melainkan dapat menampilkan informasi apa pun yang diinginkan dan tidak terbatas pada sebuah ukuran kertas (Hasan, 2016). Kartu bisnis juga masih merupakan cara terbaik yang dapat digunakan untuk memperkenalkan diri pada orang lain pada sebuah pertemuan bisnis, sehingga pendekatan yang dilakukan harus lebih inovatif dan berbeda dari yang lain agar lebih berkesan dan mudah diingat.

Penggunaan kartu bisnis konvensional sampai saat ini hanya dapat menampilkan informasi berupa tulisan dan terkadang terdapat tambahan grafis berupa 2D. Informasi berupa tulisan memiliki keterbatasan dalam penyampaian informasi yang diinginkan. Penggunaan grafis 2D dirasa kurang dapat menyampaikan informasi yang diharapkan. Seseorang akan lebih mudah dalam memahami, menangkap dan mengingat informasi yang diberikan dengan melihat, mendengar dan melakukan interaksi. Animasi 3D disertai audio yang interaktif akan memberikan pengalaman yang lebih mudah dipahami dan diingat oleh pengguna. Salah satu inovasi yang dapat dilakukan dengan bantuan teknologi Augmented Reality. Dengan penggunaan teknologi $\mathrm{AR}$, memungkinkan untuk kartu bisnis konvensional menjadi kartu bisnis digital (Virtual Business Card) yang sangat menarik karena akan lebih ekspresif, inovatif, dan kreatif dalam menampilkan informasi (Affan, Suryanto and Arfriandi, 2018). Virtual Business Card akan dapat menampilkan banyak informasi yang diinginkan, tidak hanya berfungsi menampilkan data informasi pribadi. Namun juga bisa menampilkan gambar, video, company profile, dokumen, bahkan sampai 3D model. AR dapat memberikan pengelaman baru berupa deskripsi secara visual. Selain itu, Virtual Business Card memungkinkan akses informasi kontekstual di mana pun.

AR sendiri secara umum merupakan teknologi yang menggabungkan benda nyata berupa dua dimensi dan ataupun tiga dimensi ke dalam sebuah lingkungan nyata tiga dimensi lalu memproyeksikan benda - benda maya tersebut dalam waktu nyata (Azuma, 1997, p.2). AR dikategorikan menjadi dua berdasarkan metode pelacakan (tracking), yaitu marker based tracking dan markerless (Apriyani, Huda and Prasetyaningsih, 2016, p.64). AR Markerless sendiri merupakan salah satu metode yang dikembangkan dengan tujuan untuk mengurangi penggunaan marker dalam menampilkan komponenkomponen digital dengan tools yang telah disediakan Qualcomm berbasis mobile device. Qualcomm sudah mengembangkan berbagai macam markerless tracking seperti Face Tracking, 3D Object Tracking, dan Motion Tracking. Salah satu SDK yang telah di kembangan oleh Qualcomm adalah Vuforia. Vuforia menerapkan metode FAST (Features from Accelerate Segment Test) yang menitikberatkan pendeteksian pada titik-titik (Interest View) atau sudut pada sebuah gambar. Di dalam menu Vuforia sendiri terdapat 4 jenis pemanfaatan marker yang bisa digunakan yaitu bentuk single image, cylinder, cuboid, dan 3D object.

Pemanfaatan marker single image biasanya menggunakan media buku, kertas, dan kartu. Seperti yang dilakukan oleh (Prabowo, Listyorini and Jazuli, 2015), dan (Sany and Suheri, 2014) dengan menggunakan sebuah KTP, (Seto, Listyorini and Susanto, 2015) yang menggunakan uang kertas Indonesia, dan (Putra, Wardhono and Akbar, 2018) yang menggunakan kartu permainan sebagai marker. Marker sendiri memiliki peranan yang penting agar isi dalam aplikasi AR bisa dapat tersampaikan dengan baik.

Pengembangan teknologi AR untuk mengoptimalkan sebuah produk di bidang ekonomi telah banyak mendapatkan dampak yang baik, sehingga peneliti ingin membuat sebuah Virtual Business Card yang dapat lebih relevan dengan perkembangan zaman karena bisa menampilkan berbagai informasi yang di inginkan dan tentunya inovasi yang membuatnya unik dan berbeda dari kartu bisnis konvensional biasa. Penelitian terkait pembuatan kartu bisnis/informasi digital sendiri juga bukanlah hal yang baru. Penelitian yang dilakukan (Adidrana et al., 2013) dengan membuat sebuah portofolio digital karya seni seseorang. input yang digunakan masih menggunakan webcam dan output nya pada sebuah monitor, dan masih berupa grafis 2D. Selain itu terdapat penelitian yang difokuskan untuk pengembangan aplikasi kartu nama berbasis android yang difokuskan pada portabilitas aplikasi (Syukri and Setiawan, 2017). Beberapa penelitian terdahulu kebanyakan menggunakan marker berupa kartu seperti kartu nama, KTP, uang kertas, dan kartu 
permainan. Bentuk informasi yang ditampilkan kebanyakan masih berupa teks, gambar, dan objek 3D diam. Sebagian besar penelitian yang pernah dilakukan sebelumnya lebih ke arah menyediakan informasi data umum. Masih jarang ditemukan penelitian mengenai pengembangan aplikasi menggunakan AR yang difokuskan pada fitur tampilan informasi yang cukup lengkap, seperti, teks, audio, gambar, grafis 2D, dan 3D yang lebih interaktif, serta tautan aplikasi dengan social media.

Penelitian ini dilakukan dengan menggunakan metode Agile Development jenis Extreme Programming (XP) yang mengutamakan fleksibilitas pada perubahan-perubahan yang terjadi selama pengembangan. Metode ini dipilih karena memungkinkan terjadinya perubahan-perubahan yang terjadi selama pengembangan (fleksibel) dan mementingkan komunikasi.

Berdasarkan uraian di atas, tujuan dari penelitian yang dilakukan adalah untuk menghasilkan aplikasi Virtual Business Card Berbasis Android Menggunakan Augmented Reality yang dapat menampilkan data-data informasi yang sebelumnya tidak dapat ditampilkan dan menjadi lebih interaktif, sehingga dapat menarik minat pengguna

\section{METODE PENELITIAN}

Model pengembangan software yang digunakan pada penelitian ini adalah Agile Development jenis Extreme Programming (XP). XP ini dipilih karena aplikasi yang akan dibuat tidak terlalu kompleks dan termasuk ke dalam aplikasi yang berskala kecil, dengan waktu pengembangan yang tidak terlalu lama. Penyederhanaan dalam tahapan pengembangan perangkat lunak ini bertujuan agar proses pengembangan menjadi lebih adaptif dan fleksibel dengan hasil yang tetap berkualitas.

Pressman \& Maxim (2015: 66) menjelaskan bahwa Agile Development ini menggabungkan filosofi dan seperangkat pedoman pengembangan. Filosofi kepuasan terhadap pelanggan mendorong dan mempercepat pengiriman software secara bertahap, tim proyek yang cukup kecil, bermotivasi tinggi, pekerja minimum serta penyederhanaan dalam pengembangan software secara keseluruhan. Sedangkan pedoman pengembangan memiliki pengertian bahwa pengembang dan pelanggan harus selalu aktif bekerja sama, berkomunikasi dan berkesinambungan dengan baik. Model Agile Development jenis Extreme Programming (XP) cenderung menggunakan pendekatan ObjectOriented. Tahapan-tahapan prosedur yang digunakan dalam pengembangan aplikasi Virtual Business Card dapat dilihat pada Gambar 1 (Pressman and Maxim, 2015, p.72), yang terdiri dari: planning, design, coding, dan testing.

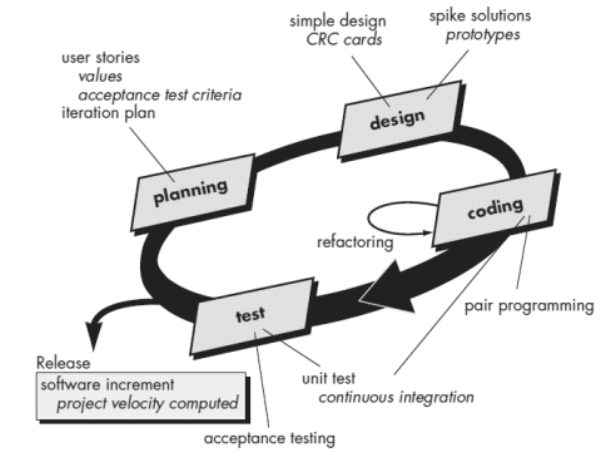

Gambar 1. Proses metode Agile development jenis Extreme Programming

Pada tahap planning dimulai dengan aktivitas (1) mengidentifikasi permasalahan yang ada, pada penelitian ini permasalahan yang muncul adalah kartu bisnis konvensional terbatas dalam menampilkan informasi yang diinginkan, dan kartu bisnis konvensional sebagai media informasi dan promosi terlalu monoton dan tidak menarik. (2) user stories, untuk menggambarkan fitur, fungsi dan lama pengerjaan yang dibutuhkan dalam pembuatan software. (3) menentukan tujuan aplikasi, yaitu untuk dapat mengembangkan aplikasi virtual business card sebagai media informasi portofolio pribadi secara AR. (4) mengidentifikasi kebutuhan perangkat keras dan lunak guna pembuatan aplikasi, yaitu: Perangkat Keras terdiri dari, Operating System Windows 10 Education, Unity 3D, Blender, Adobe Photoshop CC 2019, Adobe Illustrator CC 2019, CorelDraw Graphics Suite X7, dan Library Vuforia. Perangkat Lunak terdiri dari Personal Computer, Smartphone, Mouse dan Webcam.

Dari perangkat tersebut, kemudian peneliti dapat membuat aplikasi berbasis android. (5) membuat use case sebagai gambaran umum aplikasi, (6) membuat sequence diagram, dan (7) membuat activity diagram, untuk mengetahui proses penggunaan aplikasi ini.

Pada tahap design, yang dilakukan adalah (1) perancangan class yang dibutuhkan, dengan CRC Card. (2) merancang design GUI (graphics user interface). Kemudian, pada tahap coding hasil rancangan design akan diimplementasikan ke dalam bahasa pemrograman c\# menggunakan aplikasi Unity 3D sebagai aplikasi utama pembuatan aplikasi ini.

Pada tahap testing, peneliti melakukan pengujian dengan menggunakan (1) pengujian alpha, yaitu uji black box. (2) pengujian beta, yaitu uji ahli media dan uji respons pengguna, guna mengetahui ketertarikan pengguna untuk menggunakan aplikasi.

\subsection{Subjek Uji Coba}

Subjek uji coba pada penelitian ini adalah 57 mahasiswa program studi Pendidikan Teknik Informatika Dan Komputer tahun angkatan 2015, Universitas Negeri Semarang (UNNES) yang memiliki latar belakang keahlian, dan pekerjaan yang 
berbeda-beda. Sehingga akan memberikan sudut pandang dan masukan terhadap aplikasi lebih kompleks. Peneliti menggunakan rumus Isaac dan Michael dengan tingkat kesalahan atau sampling error dalam menentukan jumlah sampel yaitu pada tingkat kesalahan 5\%, di mana jumlah populasi dalam penelitian ini berjumlah 67.

Kemudian, selaku penguji ahli media aplikasi terdiri dari 3 Dosen UNNES, yaitu bapak Heri Triluqman Budisantoso, S.Pd., M.Pd., Ibu Sony Zulfikasari, S.Pd., M.Pd., dan Bapak Basuki Sulistio, S. Pd., M. Pd.

\subsection{Teknik Pengumpulan Data}

Pada penelitian ini teknik pengumpulan data menggunakan angket atau kuesioner untuk mengetahui kelayakan, kualitas dari aplikasi dan minat pengguna untuk menggunakan aplikasi ini. Angket atau kuesioner sendiri merupakan teknik pengumpulan data di mana partisipan responden mengisi pertanyaan atau pernyataan kemudian setelah diisi dengan lengkap mengembalikan kepada peneliti (Sugiyono, 2017, p.216). Angket pada penelitian yang digunakan berjenis angket tertutup. Berikut ini kisi-kisi angket media pada Tabel 1 (Axelius et al., 2019) dan pertanyaan pada uji respons pengguna pada Tabel 2 (Sharfina and Santoso, 2017).

\begin{tabular}{|c|c|c|c|}
\hline Aspek & Indikator & $\begin{array}{l}\text { No. } \\
\text { Soal }\end{array}$ & Jumlah \\
\hline \multirow{3}{*}{$\begin{array}{l}\text { Aspek } \\
\text { Functionality }\end{array}$} & Suitability & $1,2,3$ & 3 \\
\hline & Accurateness & $\begin{array}{r}4,5,6 \\
7,8,9\end{array}$ & 6 \\
\hline & Interoperability & 10,11 & 2 \\
\hline \multirow{4}{*}{$\begin{array}{l}\text { Aspek } \\
\text { Usability }\end{array}$} & Understandability & $\begin{array}{c}1,2,3 \\
4,5,6 \\
7,8,9 \\
10\end{array}$ & 10 \\
\hline & Learnability & 11,12 & 2 \\
\hline & Operability & $\begin{array}{c}13,14 \\
15\end{array}$ & 3 \\
\hline & Attractiveness & $\begin{array}{l}16,17 \\
18,19 \\
20,21 \\
22,23, \\
24,25 \\
26\end{array}$ & 11 \\
\hline $\begin{array}{l}\text { Aspek } \\
\text { Portability }\end{array}$ & Instability & $\begin{array}{c}1,2,3 \\
4,5\end{array}$ & 5 \\
\hline
\end{tabular}

Tabel 2. Pertanyaan Kuesioner SUS (System Usability Scale)

\begin{tabular}{|c|c|}
\hline No. & Pertanyaan \\
\hline 1. & $\begin{array}{l}\text { Saya tertarik untuk menggunakan aplikasi ini lebih } \\
\text { sering dalam menampilkan informasi pribadi secara } \\
\text { digital }\end{array}$ \\
\hline 2. & $\begin{array}{l}\text { Saya menemukan bahwa aplikasi ini rumit untuk } \\
\text { digunakan dalam menampilkan informasi pribadi secara } \\
\text { digital }\end{array}$ \\
\hline 3. & $\begin{array}{l}\text { Saya tertarik menggunakan aplikasi ini karena mudah } \\
\text { digunakan dalam menampilkan informasi pribadi secara } \\
\text { digital. }\end{array}$ \\
\hline 4. & $\begin{array}{l}\text { Saya pikir saya membutuhkan bantuan orang lain atau } \\
\text { teknisi dalam menggunakan aplikasi ini. }\end{array}$ \\
\hline 5. & $\begin{array}{l}\text { Saya merasa berbagai fitur aplikasi ini terintegrasi } \\
\text { dengan baik untuk menampilkan informasi pribadi } \\
\text { secara digital. }\end{array}$ \\
\hline
\end{tabular}

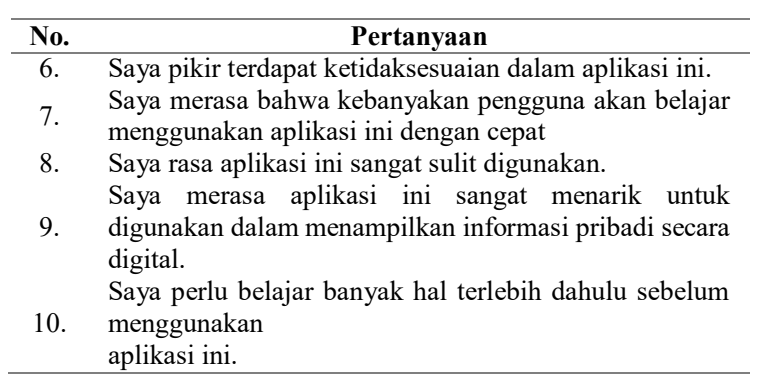

\subsection{Teknik Analisis Data}

Data pada penelitian kemudian di analisis secara kualitatif dan kuantitatif. Menurut (Sugiyono, 2017, p.7), Data kualitatif ini berupa kritik, saran maupun tanggapan pada kualitas aplikasi. Sedangkan data kuantitatif adalah data yang dinyatakan dalam angka yang didapatkan dari hasil ahli media, dan responden setelah melakukan pengujian pada aplikasi.

Hasil dari data kuesioner pada ahli media dan respons pengguna kemudian akan di konversi dari data kuantitatif ke kualitatif, pada Tabel 3 digolongkan berdasarkan kriteria penilaian (Sugiyono, 2017, p.166), dan rentang skor SUS menurut (Bangor, Kortum and Miller, 2008) yang terlihat pada Tabel 4 .

Tabel 3. Kriteria Kelayakan Media

\begin{tabular}{cc}
\hline Persentase & Kriteria \\
\hline $81,25 \%>$ skor $\leq 100 \%$ & Sangat Layak/Sangat Baik \\
$62,50 \%>$ skor $\leq 81,25 \%$ & Layak/Baik \\
$43,75 \%>$ skor $\leq 62,50 \%$ & Kurang Layak/Kurang Baik \\
$25 \% \geq$ skor $\leq 43,75 \%$ & Tidak Layak/Tidak Baik \\
\hline
\end{tabular}

Tabel 4. Kriteria Respons Pengguna Pada Kuesioner SUS (System Usability Scale)

\begin{tabular}{cc}
\multicolumn{2}{c}{ (System Usability Scale) } \\
\hline Rentang skor SUS & Kriteria \\
\hline$<50$ & Not Acceptable \\
$50-70$ & Marginal \\
$>70$ & Acceptable \\
\hline
\end{tabular}

\section{HASIL PEMBAHASAN}

Pada bagian ini akan membahas lebih lanjut mengenai planning, design, coding, dan testing dari aplikasi virtual business card dengan metode agile development jenis Extreme Programming (XP).

\subsection{Hasil Pengembangan}

\subsubsection{Planning}

1) Analisis Kebutuhan Aplikasi

Pada analisis kebutuhan untuk pengembangan aplikasi Virtual Business Card, peneliti melakukan analisis informasi (feature) yang perlu di tampilkan pemilik Virtual Business Card pada Bima Agung Setya Budi selaku subjek penelitian pemilik kartu, analisis kebutuhan software dan hardware yang digunakan dalam proses pembuatan aplikasi. Informasi (feature) yang perlu di tampilkan pemilik dalam aplikasi Virtual Business Card, dapat dilihat pada Tabel 5 sebagai berikut: 
Tabel 5. Informasi (feature) pada menu utama AR

\begin{tabular}{|c|c|c|}
\hline No. & Feature & Keterangan \\
\hline 1. & Info profil diri & $\begin{array}{l}\text { Pengenalan dan } \\
\text { singkat informasi } \\
\text { kelompok pribadi, } \\
\text { Ditampilkan pada menu utama } \\
\text { AR Intro dan Video. }\end{array}$ \\
\hline 2. & $\begin{array}{l}\text { Curriculum } \\
\text { Vitae } \\
\text { Dan Biodata }\end{array}$ & $\begin{array}{l}\text { Informasi riwayat hidup yang } \\
\text { dapat ditampilkan pada menu } \\
\text { utama AR Biodata dan Video. }\end{array}$ \\
\hline 3. & $\begin{array}{l}\text { Hasil karya dan } \\
\text { pencapaian }\end{array}$ & $\begin{array}{l}\text { Contoh hasil karya atau capaian } \\
\text { yang diraih yang ditampilkan } \\
\text { pada menu utama AR Galeri. }\end{array}$ \\
\hline 4. & Kontak & $\begin{array}{l}\text { Berisi berbagai social media, } \\
\text { email, dan sarana komunikasi lain } \\
\text { yang dibutuhkan. Ditampilkan } \\
\text { pada menu utama AR Kontak. }\end{array}$ \\
\hline 5. & $\begin{array}{l}\text { 3D object } \\
\text { person }\end{array}$ & $\begin{array}{l}\text { Tampilan gambaran pemilik kartu } \\
\text { (person) atau logo bisnis. }\end{array}$ \\
\hline 6. & Share & $\begin{array}{l}\text { Screenshot gambar tampilan } \\
\text { penggunaan aplikasi yang dapat } \\
\text { disimpan pada perangkat dan } \\
\text { dapat dibagikan. Terdapat pada } \\
\text { feature menu utama AR } \\
\text { Screenshot. }\end{array}$ \\
\hline
\end{tabular}

Selanjutnya yaitu analisis spesifikasi perangkat untuk menjalankan aplikasi yang telah dibuat dari Unity $3 \mathrm{D}$, yang dapat dilihat pada Tabel 6 .

Tabel 6 Spesifikasi Perangkat

\begin{tabular}{cc}
\hline Sistem Operasi & Android 9.0 Lollipop \\
\hline RAM & $4 \mathrm{~GB}$ \\
\hline Kamera & $25 \mathrm{MP}$ \\
\hline
\end{tabular}

\section{2) Membuat User Stories}

User stories merupakan inti dari perencanaan dan penjelasan fitur-fitur fungsional dari aplikasi. Berikut Tabel 7, user stories dari aplikasi Virtual Business Card.

Tabel 7. User Stories

Story 1: Pengguna dapat membuka aplikasi di perangkat mobile android

1 week

Story 2: Pengguna dapat membuka menu petunjuk penggunaan untuk mengetahui cara penggunaan aplikasi

1 week

Story 3: Pengguna dapat membuka menu Profil

1 week

Story 4: Pengguna dapat membuka menu Pengaturan untuk mengatur suara latar aplikasi, melihat info, dan unduh

marker.

1 week

Story 5: Pengguna dapat membuka dan menampilkan 3D profil pemilik kartu dengan memilih menu Mulai $A R$ dan mengarahkan kamera ke Virtual Business Card

4 weeks

Story 6: Pengguna dapat menampilkan pengenalan informasi singkat dari pemilik kartu dengan menge-klik intro

3 weeks

Story 7: Pengguna dapat menampilkan informasi profil dari pemilik kartu dengan menge-klik biodata

\begin{tabular}{l}
\hline 3 weeks \\
\hline Story $8:$ Pengguna dapat menampilkan informasi galeri \\
pemilik berupa kumpulan gambar \\
\hline 3 weeks \\
\hline Story 9: Pengguna dapat menampilkan menu screenshot \\
untuk mengambil gambar tampilan layar dari aplikasi Virtual \\
Business Card dan gambar akan tersimpan di penyimpanan \\
smartphone. \\
\hline 3 weeks \\
\hline Story 10: Pengguna dapat menampilkan video profil dari \\
pemilik kartu dengan menge-klik video \\
\hline 3 weeks \\
\hline Story 11: Pengguna dapat menampilkan kontak dari pemilik \\
kartu seperti membuka Instagram, Facebook, Youtube, \\
LinkedIn, dan mengirim email. Dengan cara menge-klik \\
kontak. \\
\hline 4 weeks \\
\hline Story 12: Pengguna dapat menampilkan masing-masing \\
informasi di kontak secara langsung yang di Link-kan pada \\
aplikasi di perangkat mobile android \\
\hline 3 weeks \\
\hline Story 13: Pengguna dapat menampilkan informasi pada lebih \\
dari satu Virtual Business Card \\
\hline 2 weeks
\end{tabular}

3) Membuat Use Case sebagai gambaran umum aplikasi

Use case digunakan untuk dapat menggambarkan interaksi yang terjadi antara user dengan system. Berikut Gambar 2 sampai Gambar 4, Use case dari aplikasi virtual business card.

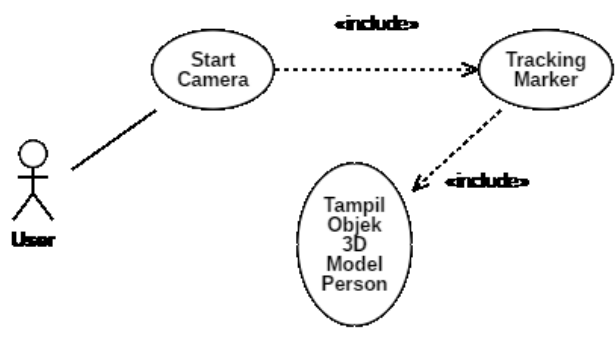

Gambar 2. Use Case Versi 1

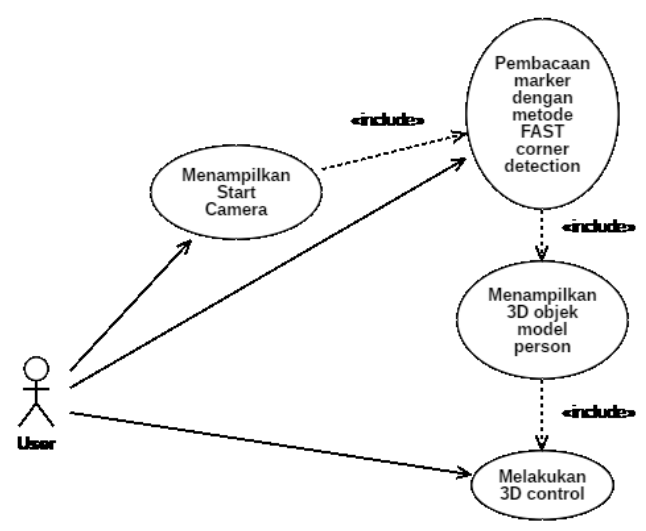

Gambar 3. Use Case Versi 2 


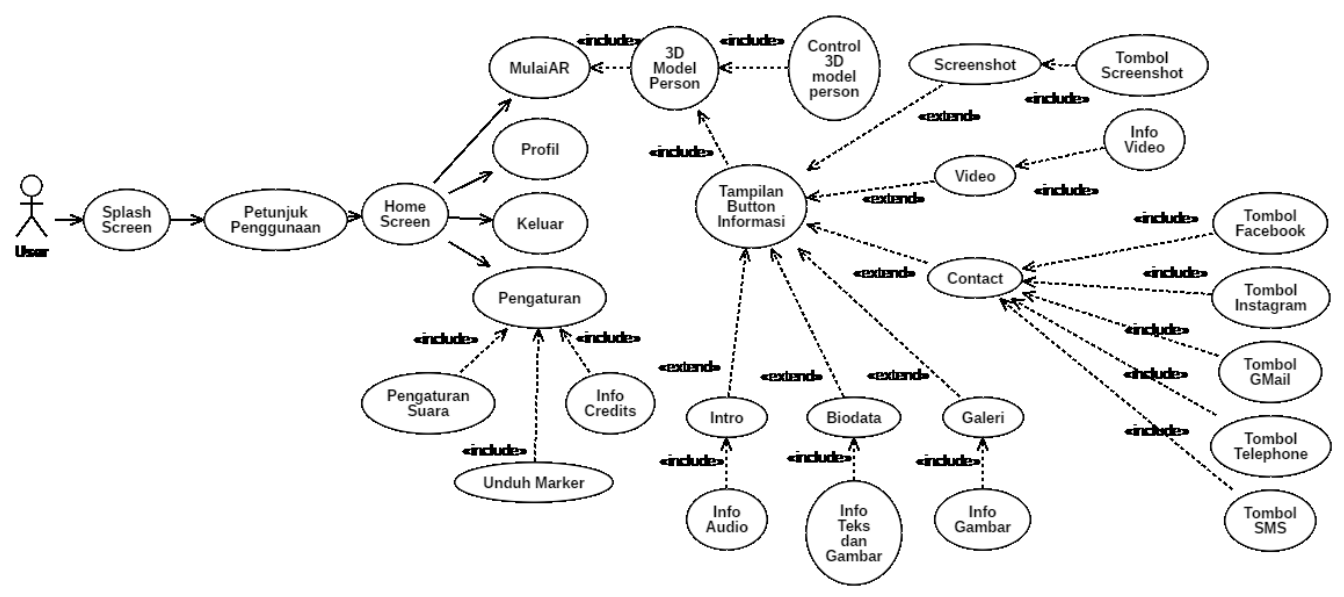

4) Membuat Sequence Diagram

Sequence Diagram dibuat untuk menggambarkan perilaku objek seperti user dan aplikasi pada use case dengan mendeskripsikan waktu hidup objek dan pesan yang dikirimkan atau diterima antar objek dalam aplikasi Virtual Business Card. Berikut sequence diagram yang menampilkan fungsi AR Kamera dapat berjalan dalam aplikasi, dapat di lihat pada Gambar 5.

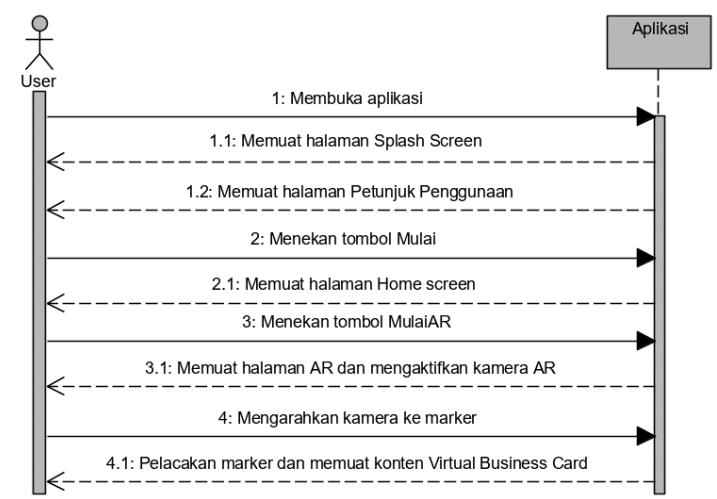

Gambar 5. Sequence Diagram Fungsi AR Kamera

5) Membuat Activity Diagram sebagai gambaran aktivitas aplikasi

Activity diagram ini berfungsi untuk mengetahui penggunaan aplikasi seperti ketika membuka menu Mulai AR, sebagaimana dapat dilihat pada Gambar 6.

\subsubsection{Design}

Design di Extreme Programming menggunakan prinsip KIS (Keep It Simple). Desain akan berisi semua implementasi dari stories tanpa adanya pengurangan ataupun penambahan. Desain ini merupakan representasi dari sistem, guna mempermudah pengembang dalam membuat aplikasi. Pada design perancangan aplikasi terdiri dari beberapa bagian, di antaranya sebagai berikut:

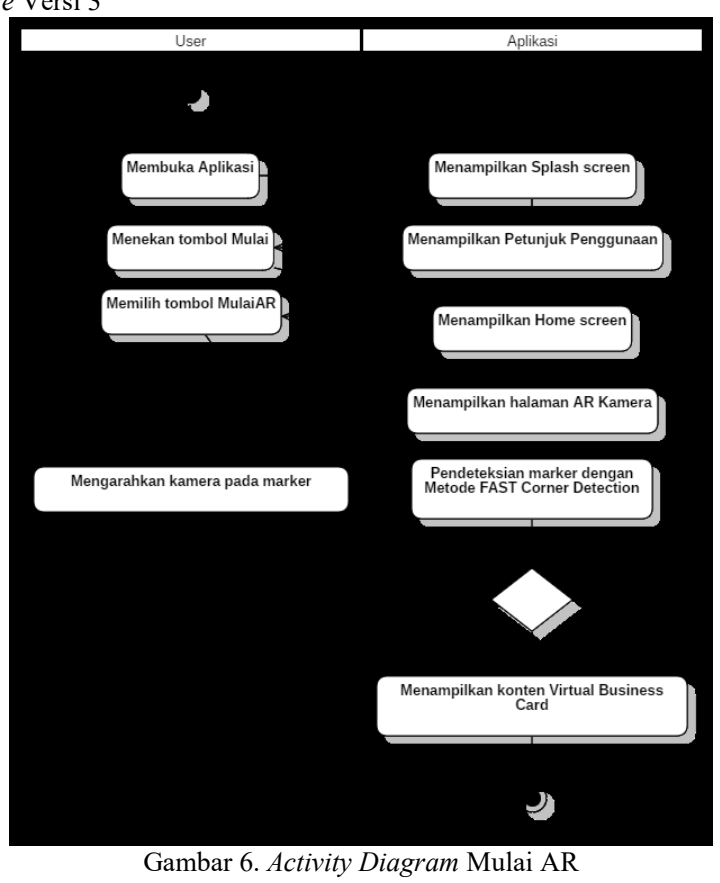

1) Perancangan class yang dibutuhkan dengan CRC Pada tahap ini bertujuan untuk mengelompokkan fungsi-fungsi yang ada pada system dan membaginya ke dalam kelas-kelas, seperti yang terlihat pada Tabel 8.

Tabel 8. CRC (Class-Responsibility Collaborator) Card

\begin{tabular}{|c|c|}
\hline \multicolumn{2}{|l|}{ Splash Screen } \\
\hline $\begin{array}{l}\text { Responsibility } \\
\text { Loading selama } 3 \text { menit dan ke petunjuk } \\
\text { penggunaan screen }\end{array}$ & $\begin{array}{l}\text { Collaborator } \\
\text { Aplikasi }\end{array}$ \\
\hline \multicolumn{2}{|c|}{ Petunjuk Penggunaan Screen } \\
\hline Responsibility & Collaborator \\
\hline $\begin{array}{l}\text { Penjelasan tentang petunjuk penggunaan } \\
\text { aplikasi }\end{array}$ & Aplikasi \\
\hline Klik tombol OK, untuk menuju ke & User \\
\hline Home Screen & Aplikasi \\
\hline \multicolumn{2}{|l|}{ Home screen } \\
\hline Responsibility & Collaborator \\
\hline Klik tombol Mulai $A R$ & User \\
\hline Klik tombol Profil & User \\
\hline Klik tombol Pengaturan & User \\
\hline
\end{tabular}




\begin{tabular}{|c|c|}
\hline \multicolumn{2}{|l|}{ Home screen } \\
\hline Klik tombol Keluar & User \\
\hline \multicolumn{2}{|l|}{ Profil } \\
\hline Responsibility & Collaborator \\
\hline $\begin{array}{l}\text { Menunjukkan profil dari pengembang } \\
\text { aplikasi }\end{array}$ & Aplikasi \\
\hline \multicolumn{2}{|l|}{ Pengaturan } \\
\hline Responsibility & Collaborator \\
\hline Klik tombol Suara & User \\
\hline Klik tombol info & User \\
\hline Klik tombol unduh Marker & User \\
\hline \multicolumn{2}{|l|}{ Suara } \\
\hline Responsibility & Collaborator \\
\hline $\begin{array}{l}\text { Menghidupkan dan mematikan suara } \\
\text { latar aplikasi }\end{array}$ & Aplikasi \\
\hline \multicolumn{2}{|l|}{ Info } \\
\hline Responsibility & Collaborator \\
\hline $\begin{array}{l}\text { Menampilkan info penggunaan pada } \\
\text { aplikasi }\end{array}$ & Aplikasi \\
\hline \multicolumn{2}{|l|}{ Keluar } \\
\hline Responsibility & Collaborator \\
\hline Klik tombol Icon $Y A$, untuk keluar dari & User \\
\hline aplikasi & Aplikasi \\
\hline Klik tombol Icon Tidak, untuk kembali & User \\
\hline ke Home Screen & Aplikasi \\
\hline \multicolumn{2}{|l|}{ Mulai $A R$} \\
\hline Responsibility & Collaborator \\
\hline $\begin{array}{l}\text { Kamera di hadapkan, lalu scan marker } \\
\text { berupa kartu bisnis konvensional dan } \\
\text { bila terdeteksi akan menuju Menu } \\
\text { Informasi AR Business Card }\end{array}$ & Aplikasi \\
\hline Klik tombol flash, untuk menghidupkan & User \\
\hline dan mematikan lampu flash & Aplikasi \\
\hline Klik tombol keluar, untuk kembali ke & User \\
\hline Home screen & Aplikasi \\
\hline \multicolumn{2}{|c|}{ Menu Informasi AR Business Card } \\
\hline Responsibility & Collaborator \\
\hline Klik tombol biodata, untuk & User \\
\hline $\begin{array}{l}\text { menampilkan informasi profil dari } \\
\text { pemilik kartu }\end{array}$ & Aplikasi \\
\hline Klik tombol video, untuk menampilkan & User \\
\hline informasi berupa video & Aplikasi \\
\hline Klik tombol intro, untuk menampilkan & User \\
\hline pengenalan informasi berupa audio & Aplikasi \\
\hline Klik tombol galeri, untuk & User \\
\hline menampilkan informasi berupa gambar & Aplikasi \\
\hline Klik tombol screenshot, untuk & User \\
\hline mengambil gambar layar dari aplikasi & Aplikasi \\
\hline Klik tombol Kontak, untuk & User \\
\hline menampilkan tombol kontak seperti & Aplikasi \\
\hline $\begin{array}{l}\text { Facebook, Instagram, YouTube, } \\
\text { LinkedIn, dan Gmail }\end{array}$ & \\
\hline
\end{tabular}

\section{2) Pemodelan}

Pada tahap ini desain 2D dibangun menggunakan software grafis Corel Draw, Adobe Photoshop dan Adobe Illustrator seperti pada Gambar 7 sampai Gambar 11. Setelah desain grafis dibuat, maka tampilan (interface) aplikasi dan layout-nya dibuat di dalam Unity 3D.

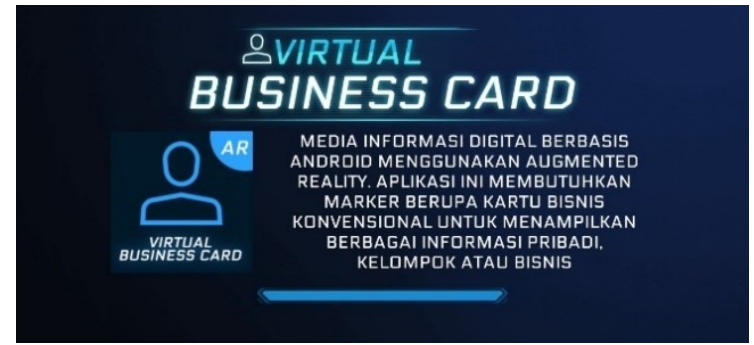

Gambar 7. Splash Screen

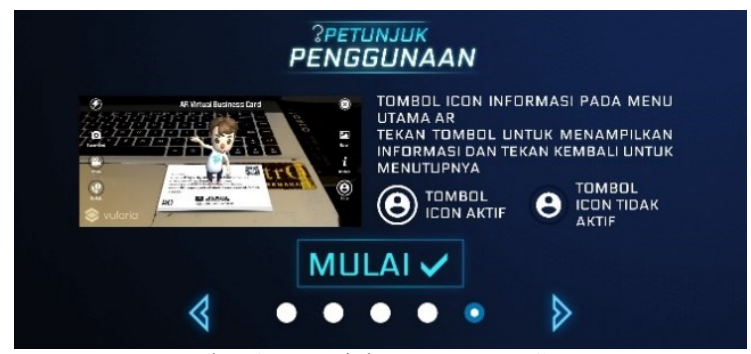

Gambar 8. Petunjuk Penggunaan Screen

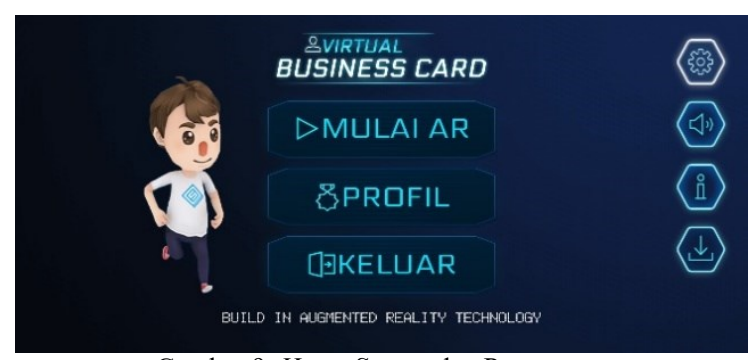

Gambar 9. Home Screen dan Pengaturan
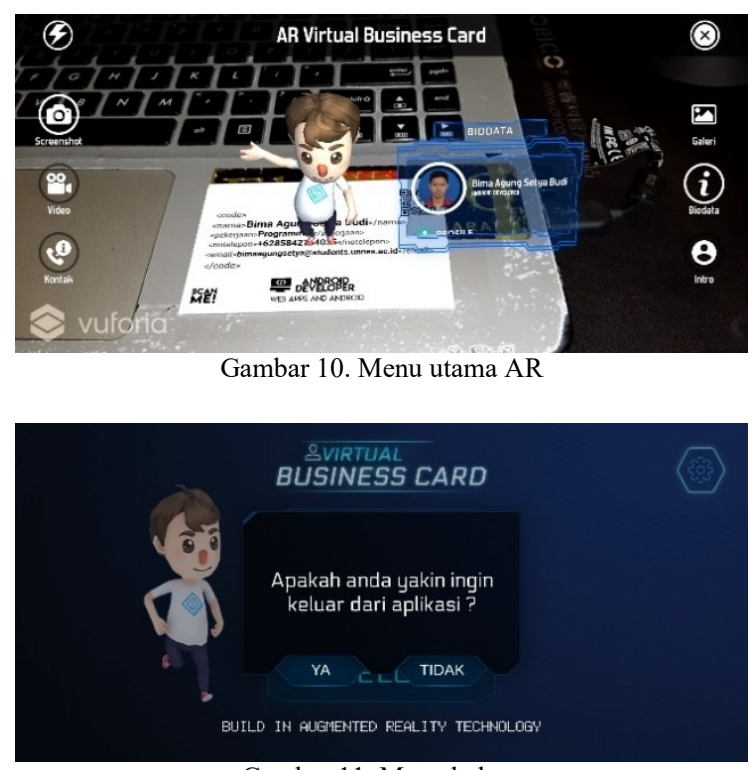

Gambar 11. Menu keluar

\subsubsection{Coding}

Pada tahap coding ini, hasil rancangan design akan diimplementasikan ke dalam bahasa pemrograman. Kemudian dilakukan pembuatan marker untuk menampilkan informasi secara digital. Berikut kartu bisnis konvensional dengan ukuran 51 x $89 \mathrm{~mm}$ yang digunakan sebagai marker pada Gambar 12 . 


\section{品此品 \\ $<$ code $>$ \\ $<$ nama $>$ Bima Agung Setya Budi $</$ nama $>$ \\ $<$ pekerjaan>Programmer</pekerjaan> \\ <notelepon>+6285842754035</notelepon> \\ <email>bimaagungsetya@students.unnes.ac.id</email> \\ $<$ code $>$}

\section{$\begin{array}{ll}\text { SCAN } & \langle\mathrm{I}\rangle \\ \text { MEINERELOPER } & \text { WEB APPS AND ANDROID }\end{array}$}

Gambar 12. Marker kartu bisnis konvensional

Objek 3D pada aplikasi ini untuk model person di ambil melalui assets store yang terdapat pada Unity Assets Store. 3D model person yang digunakan adalah Character Pack: Free Sample by SUPERCYAN. Untuk pengembangan sesuai keperluan pengguna, 3D model person dapat dibuat menggunakan aplikasi Blender.

Pengembangan aplikasi Virtual Business Card ini menggunakan bahasa pemrograman $\mathrm{C} \#$ untuk pembuatan script dan software Unity 3D, sebagai software utama dalam pembuatan aplikasi ini. Untuk meminimalisir kemungkinan munculnya bug, maka dilakukan refactoring pada tahap coding ini. Proses terakhir dalam pembuatan aplikasi Virtual Business Card yaitu build aplikasi di pada Unity 3D ke Android agar aplikasi dapat diuji langsung dan digunakan di perangkat Android.

\subsubsection{Testing}

Tahap selanjutnya yang dilakukan setelah pembuatan aplikasi selesai, dilakukan tahapan pengujian. Pengujian yang pertama dilakukan adalah pengujian alpha dengan metode Black box, yang berfokus pada aspek functionality. Kemudian melakukan pengujian beta dengan kuesioner untuk uji validitas media dan responden, yang berfokus pada aspek usability. Sehingga aplikasi Virtual Business Card dapat dinyatakan kelayakannya untuk digunakan pengguna.

\subsection{Hasil Uji Coba}

Aplikasi Virtual Business Card adalah aplikasi AR berupa portofolio digital menggunakan marker berupa kartu bisnis konvensional. Aplikasi ini ditujukan untuk keperluan pribadi, kelompok atau organisasi dan bisnis. Guna menampilkan profil diri, informasi perusahaan/bisnis, personal branding, dan profesionalitas. Aplikasi yang dihasilkan pada penelitian ini adalah berupa perangkat lunak (software) Virtual Business Card yang terdiri dari Splash screen, Petunjuk Penggunaan Screen, Home screen, Menu Profil, Menu Pengaturan, dan Mulai AR screen. Pada halaman menu utama AR terdapat 6 tombol icon features, yaitu tombol icon intro untuk menampilkan informasi data pribadi berupa audio, tombol icon biodata untuk menampilkan informasi biodata yang dapat di scroll, tombol icon Galeri untuk menampilkan informasi project atau lainnya berupa gambar, tombol icon social media untuk menampilkan tombol social media yang dapat di teruskan pada social media pengguna. tombol icon Video untuk menampilkan informasi pribadi pengguna berupa video. Dan tombol icon screenshot untuk menangkap gambar layer dari aplikasi dan menyimpannya pada galeri sehingga dapat di bagikan. Perangkat pendukung aplikasi ini adalah kartu bisnis yang digunakan sebagai image target. Aplikasi Virtual Business Card dijalankan dengan bantuan kamera di smartphone android.

Aplikasi yang telah dibuat akan dilakukan pengujian alpha dan beta, untuk mengetahui kualitas dan kelayakan aplikasi untuk digunakan pengguna. Pada pengujian alpha dilakukan uji black box, didapatkan hasil bahwa semua menu, fungsi maupun tombol pada aplikasi dapat digunakan dengan baik dan tidak di dapatkan error karena semua tombol berfungsi dengan baik.

Pengujian beta terdiri dari uji ahli media dan respons pengguna. Hasil validitas media, aplikasi dapat dinyatakan sangat layak untuk digunakan sebagai portofolio informasi digital. Aplikasi Virtual Business Card memperoleh nilai aspek Usability 91,66\%, aspek Functionality 89,1\%, dan aspek Portability $90 \%$, dengan nilai persentase $89,88 \%$. Hasil pengujian validitas media dapat dilihat pada Tabel 9. Saran, komentar, dan kritik dari ahli media akan diperbaiki. Kemudian dilakukan pengujian pada pengguna, guna mengetahui kualitas aplikasi dan ketertarikan pengguna untuk menggunakan aplikasi Virtual Business Card.

Tabel 9. Validitas Aspek Ahli Media

\begin{tabular}{|c|c|c|c|c|c|}
\hline \multirow[t]{2}{*}{ Aspek } & \multicolumn{3}{|c|}{ Skor Ahli } & \multirow{2}{*}{$\begin{array}{c}\text { Jumlah } \\
\text { Skor }\end{array}$} & \multirow{2}{*}{$\begin{array}{c}\text { Persent } \\
\text { ase }\end{array}$} \\
\hline & 1 & 2 & 3 & & \\
\hline Usability & 42 & 43 & 36 & 121 & $\begin{array}{c}91,66 \\
\%\end{array}$ \\
\hline Functionality & 93 & 101 & 84 & 278 & $89,1 \%$ \\
\hline Portability & 19 & 20 & 15 & 54 & $90 \%$ \\
\hline Total & 154 & 164 & 135 & 453 & - \\
\hline Persentase & 91,6 & 97,6 & 80,35 & 89,88 & - \\
\hline Total & $6 \%$ & $1 \%$ & $\%$ & $\%$ & \\
\hline
\end{tabular}

Pada pengujian usability oleh ahli media ini dapat diketahui bahwa aplikasi Virtual Business Card dapat menampilkan informasi yang lebih banyak dengan bantuan teknologi augmented reality dibandingkan dengan kartu bisnis konvensional, perbandingan dapat dilihat pada Tabel 10 .

Pengujian selanjutnya dilakukan dengan menyebar kuesioner SUS (System Usability Scale). Hasil dari respons pengguna mendapatkan skor ratarata akhir sebesar 83,29\% dan masuk kriteria acceptable atau layak untuk digunakan. Dari hasil respons pengguna menunjukkan hasil yang sangat positif, sehingga dapat diketahui bahwa kualitas aplikasi dalam menampilkan informasi sudah sangat baik dan dapat menarik minat pengguna untuk menggunakan aplikasi Virtual Business Card. 
Berikut Tabel 11 hasil pengujian respons pengguna dengan SUS Kuesioner.

Tabel 10. Perbandingan informasi yang dapat di tampilkan pada

\begin{tabular}{lcc}
\multicolumn{1}{c}{ Virtual Business Card dan Kartu Bisnis Konvensional } \\
\hline Informasi Pribadi dan & $\begin{array}{c}\text { Virtual } \\
\text { Business Card }\end{array}$ & $\begin{array}{c}\text { Kartu Bisnis } \\
\text { Konvensional }\end{array}$ \\
Kontak (Teks) & $\sqrt{ }$ & $\sqrt{ }$ \\
Gambar & $\sqrt{ }$ & $\sqrt{ }$ \\
Audio & $\sqrt{ }$ & \\
Social Media Links & $\sqrt{ }$ & \\
Calling or Direct & $\sqrt{ }$ \\
Contact & & \\
Website Links & $\sqrt{ }$ \\
Videos & $\sqrt{ }$ \\
\hline 3D Models & $\sqrt{ }$ \\
Animasi Interaktif & $\sqrt{ }$ \\
Berbagi informasi kartu & $\sqrt{ }$ & $\sqrt{ }$ \\
\hline
\end{tabular}

\begin{tabular}{|c|c|c|}
\hline No. & Pertanyaan & Total \\
\hline 1. & $\begin{array}{l}\text { Saya tertarik untuk menggunakan aplikasi ini } \\
\text { lebih sering dalam menampilkan informasi } \\
\text { pribadi secara digital }\end{array}$ & 194 \\
\hline 2. & $\begin{array}{l}\text { Saya menemukan bahwa aplikasi ini rumit } \\
\text { untuk digunakan dalam menampilkan } \\
\text { informasi pribadi secara digital }\end{array}$ & 177 \\
\hline 3. & $\begin{array}{l}\text { Saya tertarik menggunakan aplikasi ini karena } \\
\text { mudah digunakan dalam menampilkan } \\
\text { informasi pribadi secara digital. }\end{array}$ & 195 \\
\hline 4. & $\begin{array}{l}\text { Saya pikir saya membutuhkan bantuan orang } \\
\text { lain atau teknisi dalam menggunakan aplikasi } \\
\text { ini. }\end{array}$ & 188 \\
\hline 5. & $\begin{array}{l}\text { Saya merasa berbagai fitur aplikasi ini } \\
\text { terintegrasi dengan baik untuk menampilkan } \\
\text { informasi pribadi secara digital. }\end{array}$ & 197 \\
\hline 6. & $\begin{array}{l}\text { Saya pikir terdapat ketidaksesuaian dalam } \\
\text { aplikasi ini. }\end{array}$ & 187 \\
\hline 7. & $\begin{array}{l}\text { Saya merasa bahwa kebanyakan pengguna } \\
\text { akan belajar menggunakan aplikasi ini dengan } \\
\text { cepat }\end{array}$ & 195 \\
\hline 8. & Saya rasa aplikasi ini sangat sulit digunakan. & 197 \\
\hline 9. & $\begin{array}{l}\text { Saya merasa aplikasi ini sangat menarik untuk } \\
\text { digunakan dalam menampilkan informasi } \\
\text { pribadi secara digital. }\end{array}$ & 196 \\
\hline 10. & $\begin{array}{l}\text { Saya perlu belajar banyak hal terlebih dahulu } \\
\text { sebelum menggunakan } \\
\text { aplikasi ini. }\end{array}$ & 173 \\
\hline & Jumlah nilai total $* 2,5$ & 4748 \\
\hline & Rata-rata skor tiap responden & 83 \\
\hline
\end{tabular}

Penelitian aplikasi Virtual Business Card berbasis android menggunakan augmented reality ini memiliki keunggulan dari produk sejenis yang ada sekarang dan penelitian-penelitian sebelumnya dari segi fitur serta visualisasi informasi portofolio digital yang lebih optimal. Fitur-fitur yang dimiliki aplikasi Virtual Business Card dalam menyampaikan informasi portofolio digital sangat lengkap seperti, penyampaian informasi dalam bentuk teks, gambar 2D, audio, video, dan 3D objek. Kemudian, terdapat fitur screenshot untuk dapat berbagi pengalaman dalam penggunaan aplikasi, QR-Code untuk memudahkan download aplikasi, dan fitur link yang dapat menautkan berbagai macam social media, kontak, dan website. Aplikasi ini juga telah berbasis mobile sehingga lebih mudah dibawa dan digunakan, karena pada penelitian sebelumnya masih ada yang menggunakan perangkat komputer. Aplikasi ini dapat menampilkan informasi lebih banyak dari kartu konvensional dengan visualisasi yang baik dan membantu pengguna untuk memperoleh informasi pada kartu bisnis lebih mudah, sehingga dapat menarik minat pengguna untuk menggunakan aplikasi.

\section{KESIMPULAN}

Berdasarkan hasil penelitian dan pembahasan, maka peneliti dapat mengambil kesimpulan sebagai berikut:

1) Pengujian alpha dengan menggunakan uji black box, menunjukkan bahwa aplikasi berjalan dengan baik dan sesuai dengan yang direncanakan.

2) Pengujian beta dilakukan dengan uji ahli media untuk mengetahui kualitas dan kelayakan aplikasi, dibagi berdasarkan aspek Usability, aspek Functionality, dan aspek Portability. Berdasarkan penilaian ahli media diperoleh hasil persentase $89,88 \%$. Di mana aspek Usability 91,66\%, aspek Functionality 89,1\%, dan aspek Portability $90 \%$. Dari hasil ini dapat diketahui bahwa aplikasi Virtual Business Card memiliki kemampuan yang baik dalam menampilkan informasi portofolio digital secara virtual dengan menarik. sehingga dapat dinyatakan sangat layak digunakan sebagai portofolio digital.

3) Hasil pengujian beta dengan menggunakan uji respons pengguna, mendapatkan skor rata-rata akhir sebesar 83, 29\%, sehingga masuk dalam kriteria acceptable atau layak untuk digunakan. Hasil respons pengguna menunjukkan hasil yang sangat positif, sehingga dapat diketahui bahwa kualitas aplikasi dalam menampilkan informasi sudah sangat baik dan pengguna tertarik untuk menggunakan aplikasi Virtual Business Card.

\section{DAFTAR PUSTAKA}

ADIDRANA, D., LUMENTA, A., SUGIARSO, B. AND TULENAN, V., 2013. Perancangan Kartu Nama dengan Augmented Reality sebagai Portofolio Digital. Jurnal Teknik Elektro dan Komputer Unsrat, [online] 2(2), pp.1-9. Available at: $<$ https://ejournal.unsrat.ac.id/index.php/elek dankom/article/view/1603>.

AFFAN, B.N., SURYANTO, A. AND ARFRIANDI, A., 2018. Implementation of augmented reality as information and promotion media on Dieng tourism area. Telkomnika (Telecommunication Computing Electronics and Control), 16(4), pp.1818-1825.

APRIYANI, M.E., HUDA, M. AND PRASETYANINGSIH, S., 2016. Analisis Penggunaan Marker Tracking Pada Augmented Reality Huruf Hijaiyah. 8(1), p.72.

AXELIUS, V., SIREN, K., SETIAWAN, N.Y. AND 
ROKHMAWATI, R.I., 2019. Evaluasi Kualitas Perangkat Lunak Menggunakan ISO / IEC 9126-4 Quality In Use ( Studi Kasus: FILKOM Apps ). 3(2), pp.16251632.

AZUMA, R.T., 1997. A survey of augmented reality. Presence: Teleoperators and Virtual Environments.

BANGOR, A., KORTUM, P.T. AND MILLER, J.T., 2008. An empirical evaluation of the system usability scale. International Journal of Human-Computer Interaction.

HASAN, A.M., 2016. Evolusi Kartu Nama. [online] www.tirto.id. Available at: $<$ https://irto.id/evolusi-kartu-nama-bL7P $>$ [Accessed 4 Oct. 2019].

PRABOWO, R., LISTYORINI, T. AND JAZULI, A., 2015. Pengenalan Rumah Adat Indonesia Berbasis Augmented Reality Dengan Memanfaatkan KTP Sebagai Marker. Prosiding SNATIF, [online] 2(2), pp.51-58. Available at: $<$ http://en.wikipedia.org/w/index.php?title= Augmented_reality\&oldid $=455741356>$.

PRESSMAN, R.S. AND MAXIM, B.R., 2015. Software Engineering: A Practitioner's Approach, Eighth Edition. ACM SIGSOFT Software Engineering Notes.

PUTRA, R.R.A., WARDHONO, W.S. AND AKBAR, M.A., 2018. Pengembangan Permainan Trading Card Augmented Reality Bertema Perang Baratayuda. Jurnal Pengembangan Teknologi Informasi dan Ilmu Komputer (J-PTIIK) Universitas Brawijaya, 2(10).

SANY, D.S. AND SUHERI, A., 2014. Pengembangan Visual Portofolio Digital Berbasis Augmented Reality Menggunakan Kartu Tanda Penduduk Dan Android. 6, pp.30-36.

SETO, M.H.N., LISTYORINI, T. AND SUSANTO, A., 2015. Pengenalan Pahlawan Indonesia Berbasis Augmented Reality Dengan Marker Uang Indonesia. Prosiding SNATIF, [online] 2(2), pp.43-50. Available at: $<$ https://ejournal.unsrat.ac.id/index.php/elek dankom/article/view/1603>.

SHARFINA, Z. AND SANTOSO, H.B., 2017. An Indonesian adaptation of the System Usability Scale (SUS). In: 2016 International Conference on Advanced Computer Science and Information Systems, ICACSIS 2016.

SUGIYONO, 2017. Metode Penelitian dan Pengembangan (Research and Development/R\&D). Bandung: Alfabeta.

SYUKRI, N. AND SETIAWAN, E.B., 2017. Aplikasi Kuartu Berbasis Android Sebagai Media Pertukaran Informasi Kartu Nama. Jurnal ULTIMATICS, 9(1), pp.25-32. 